\title{
Magnetite-Supported Gold Nanostars for the Uptake and SERS Detection of Tetracycline
}

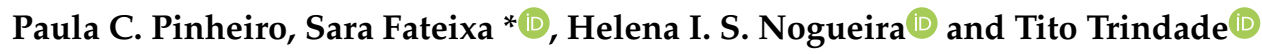 \\ Department of Chemistry, CICECO-Aveiro Institute of Materials, University of Aveiro, Campus de Santiago, \\ 3810-193 Aveiro, Portugal; pcpinheiro@ua.pt (P.C.P.); helenanogueira@ua.pt (H.I.S.N.); tito@ua.pt (T.T.) \\ * Correspondence: sarafateixa@ua.pt; Tel.: +351-234-370-726
}

Received: 20 November 2018; Accepted: 21 December 2018; Published: 27 December 2018

\begin{abstract}
Magnetite nanoparticles (MNPs) decorated with gold nanostars (AuNSs) have been prepared by using a seed growth method without the addition of surfactants or colloidal stabilizers. The hybrid nanomaterials were investigated as adsorbents for the uptake of tetracycline (TC) from aqueous solutions and subsequent detection using surface-enhanced Raman scattering (SERS). Several parameters were investigated in order to optimize the performance of these hybrid platforms on the uptake and SERS detection of TC, including variable $\mathrm{pH}$ values and the effect of contact time on the removal of TC. The spatial distribution of TC and AuNS on the hybrid composites was accomplished by coupling SERS analysis with Raman imaging studies, allowing also for the determination of the detection limit for TC when dissolved in ultrapure water $(10 \mathrm{nM})$ and in more complex aqueous matrices $(1 \mu \mathrm{M})$. Attempts were also made to investigate the adsorption modes of the TC molecules at the surface of the metal NPs by taking into account the enhancement of the Raman bands in these different matrices.
\end{abstract}

Keywords: Au nanostars; magnetite nanoparticles; water pollutants; SERS; antibiotics

\section{Introduction}

Antibiotics dissolved in natural waters are regarded as organic wastewater contaminants of general concern due to their potential risks to human health and ecosystems. The widespread use of antibiotics has increased the concerns related to the adverse contamination of waters, due to the impact on human health through direct and indirect consumption and also in the treatment of infections caused by antibiotic-resistant bacteria [1-4]. Antibiotics can be released into municipal wastewaters due to incomplete metabolism in humans or due to disposal of unused antibiotics acquired for human consumption and veterinary uses. Among the antibiotics that pose great concern as organic wastewater contaminants, there is tetracycline (TC), which is a widely used broad-spectrum antibiotic, although in the European Union it is restricted to the treatment of infectious diseases in humans and animals. Tetracyclines were first reported in the scientific literature in 1948 as natural products from the soil bacteria actinomycete [5,6]. According to the European surveillance of veterinary antimicrobial consumption, of the overall sales of antimicrobials in the 30 countries in 2015, tetracycline antibiotics represented $32.8 \%$ of the total sales for veterinary usage [7]. It has been reported that only a small portion of TC is metabolized in the organism and $70 \%$ is excreted via urine and feces in an unaltered form [8]. Indeed, the occurrence of TC has been reported in animal products and in aquatic environments from $\mathrm{ng} / \mathrm{L}$ up to $\mu \mathrm{g} / \mathrm{L}[3,8,9]$. In Europe, the maximum residues limits for TC in different animal food categories are set by Commission Regulation (EU) 37/2010 [10]. As such, water monitoring methods that allows for the detection of vestigial TC in waters are of great relevance.

Several instrumental techniques have been used for the detection of TC, including capillary electrophoresis [11], high-performance liquid chromatography [12,13], immunoassay [14], 
fluorescence-based assays [15], antibody-based electrochemical biosensors [16] and microbiological methods [17]. Although these techniques can achieve high sensitivity and selectivity, they are time-consuming and in some cases cost-intensive. Alternatively, surface-enhanced Raman scattering (SERS) spectroscopy is a sensitive vibrational technique that might allow for the trace detection of vestigial molecules adsorbed on metal surfaces, typically $\mathrm{Au}$ or $\mathrm{Ag}$ colloidal nanoparticles (NPs) [18-22]. SERS provides multiple advantages over other techniques that include the high sensitivity, spectroscopic fingerprint properties and simple sample preparation. Additionally, due to narrow well-resolved bands characteristic of inelastic light scattering, SERS can provide abundant vibrational information of the adsorbed molecules and be applied to multiplex detection. In fact, this technique has been explored for the TC detection in several types of samples [23-31]. For instance, $\mathrm{Li}$ et al. have applied Au hollow spheres to detect TC and the limit of detection reached $0.1 \mu \mathrm{g} / \mathrm{L}$ [31]. Dhakal et al. have reported a cyclodextrin-modified Ag colloid for on-site quantification of TC residues in whole milk, achieving a detection limit of $0.01 \mathrm{ppm}$, which is below the maximum residue limit (MRL) set by governmental authorities [27].

Although ultrasensitive analysis can be carried out with SERS, antibiotic compounds in natural waters are normally present in low concentration in such complex analytical matrices. An interesting possibility to circumvent this problem involves the capture of molecules of the pollutant by a sorbent material that besides allowing for pre-concentration procedures also acts as an SERS substrate for optical detection [32]. In this context, we have been interested in developing magneto-plasmonic hybrid nanomaterials that combine magnetic properties and SERS activity, thus exploring the magnetic separation ability offered by a magnetic oxide (e.g., $\mathrm{Fe}_{3} \mathrm{O}_{4}$ ) and the plasmonic behaviour of a nanometal (e.g., $\mathrm{Au}$ ) [32,33]. Several approaches have been reported in the literature to produce magneto-plasmonic nanomaterials for SERS-sensitive detection, aiming at environmental applications [32-47], but only a few reports have described the SERS detection of antibiotics [33,41,44].

In this research, we have investigated a simple and low-cost surfactant-free seed growth method to produce gold nanostars (AuNSs) supported on magnetite NPs (MNP-AuNS) envisaging their use as nanosorbents for TC extraction and detection. These multifunctional nanostructures can be used as nanosorbents for the pre-concentration of the target analyte by magnetic separation as the first operational procedure followed by SERS detection of TC in the solid phase. This enrichment procedure and the presence of AuNS in the hybrid material contribute to the enhancement of the Raman signal of the molecular probe. Therefore, these hybrid materials were evaluated for the magnetic capture and SERS detection of TC in distinct aqueous matrices, which were spiked with this antibiotic.

\section{Results and Discussion}

\subsection{Characterization of MNP-AuNS}

Figure 1 illustrates the whole procedure for the fabrication of MNP-AuNS and their use in the uptake and detection of TC by SERS. At the outset, well-defined cubic-shape $\mathrm{Fe}_{3} \mathrm{O}_{4} \mathrm{NPs}$ were first synthesized through partial oxidation of a ferrous salt in alkaline media, using $\mathrm{KNO}_{3}$ as the oxidant agent. The magnetic core ensured the convenient separation of the material from the aqueous solution and the Au nanostars at the MNP surfaces acted as SERS substrates. Hence, the MNP-AuNS nanostructures combined the SERS activity of Au NPs and the magnetic properties of $\mathrm{Fe}_{3} \mathrm{O}_{4}$ NPs. Briefly, a TC aqueous solution was mixed with MNP-AuNS hybrid substrates and then the magneto-plasmonic substrates were separated magnetically, using a magnet and washed with ultrapure water under magnetic confinement. The resultant MNP-AuNS particles with adsorbed TC were re-suspended in water and $10 \mu \mathrm{L}$ of hybrid particles were dropped on a glass substrate placed over a NdFeB laboratorial magnet. After drying in air at room temperature, the SERS analysis was conducted, with laser excitation of the TC supported onto the hybrid substrates. 
(a)

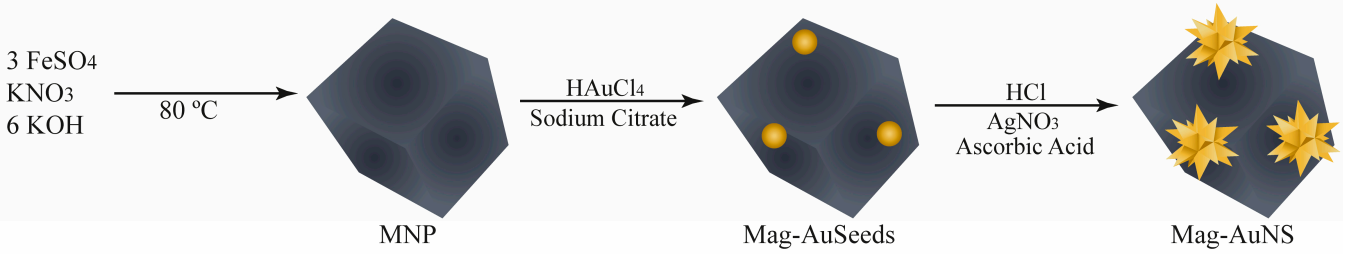

(b)

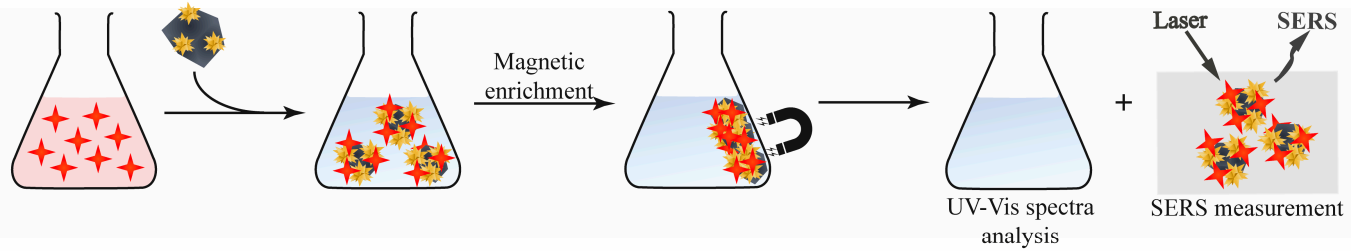

Au Seeds $\quad$ * $\quad$ H Mugnet

Figure 1. Schematic illustration of the (a) preparation of magnetite-gold nanostars (MNP-AuNS) hybrid materials; and (b) operating procedure for the magnetic uptake and surface-enhanced Raman scattering (SERS) detection of tetracycline (TC), using MNP-AuNS.

Figure 2a shows the TEM images of the MNPs, confirming that the $\mathrm{Fe}_{3} \mathrm{O}_{4}$ particles have a well-defined cubic shape and an average dimension of $80 \mathrm{~nm}$ (diagonal). Our previous work reports that the method employed results in cubic-shaped ferrimagnetic NPs with a saturation magnetization of $86 \mathrm{emu} / \mathrm{g}$ composed of magnetite as the main crystalline phase $[33,48,49]$. The surface of the as-prepared MNP was decorated with AuNS using an adaptation of the seed-mediated growth method described by Wang and co-workers [50]. Thus, Figure $2 \mathrm{~b}$ shows Au nanospheres with an average size of $14.9 \pm 3.0 \mathrm{~nm}$ covering the cubic-shaped $\mathrm{Fe}_{3} \mathrm{O}_{4} \mathrm{MNP}$. Then, these MNP-Au seeds were dispersed in an aqueous solution containing $\mathrm{Au}(\mathrm{III})$, and the solution was then acidified with $\mathrm{HCl}$, followed by simultaneous slow addition of ascorbic acid and $\mathrm{AgNO}_{3}$. According to the literature, in these conditions, the presence of $\mathrm{Ag}^{+}$plays an essential role in the growth mechanism to control the anisotropic growth of $\mathrm{Au}$ branches; ascorbic acid is responsible to reduce $\mathrm{Au}^{3+}$ to $\mathrm{Au}^{0}$; the acidic $\mathrm{pH}$ of the synthesis solution leads to more red-shifted plasmon bands because it favours the formation of larger nanostars; and the Au seeds control the AuNS size [50-53]. In the present work, the ratio between $\left[\mathrm{Au}^{3+}\right]$ and $\left[\mathrm{Au}^{0}\right]$ was set at 50, leading to the formation of AuNS with an average core size of $77.5 \pm 20.1 \mathrm{~nm}$ and several branches, as can be seen in Figure 2c. An immediate advantage of using MNPs as substrates for the AuNS growth is that the particles can be isolated efficiently from the colloid through simple magnetic separation, although it should be noticed that the use of the seed-mediated growth method to obtain AuNS on the surfaces of MNP in an acidic medium probably resulted in some detachment of Au seeds from these substrates (see Figure S1 in Supplementary Materials). Nevertheless, it was found necessary to obtain the MNPs decorated with smaller AuNSs.

The optical spectra of the different colloids were measured and presented in the Supplementary Materials (Figure S2). The addition of MNPs to the Au seeds red-shifted the localized surface plasmon resonance (LSPR) band of Au NPs and also resulted in band broadening. We attributed this behaviour to particle aggregation effects as demonstrated by SEM analysis (Figure 2b, left). Additionally, the broadening of the LSPR band for the AuNSs when interacting with the MNPs has been explained due to plasmon coupling, refractive index effects, particles' heterogeneity and tips' polydispersity. Other researchers have reported similar optical behaviour for other hybrid nanostructures, such as MNP-AuNS [54] and rGO-AuNS [50]. 

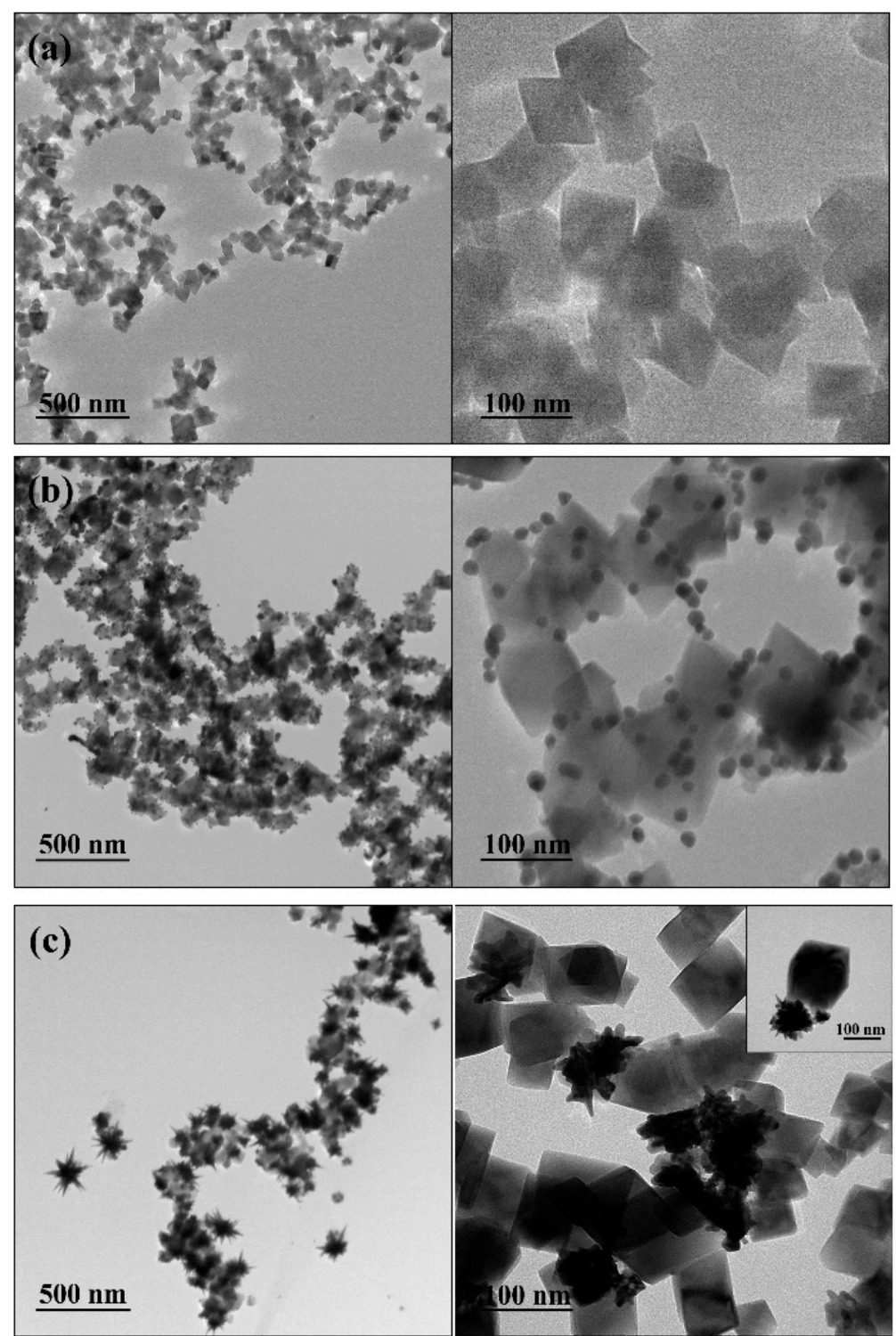

Figure 2. TEM images of (a) cubic $\mathrm{Fe}_{3} \mathrm{O}_{4}$ NPs; (b) MNP-Au seeds; and (c) MNP-AuNS (inset shows a high-magnification image).

Figure 3 shows the powder XRD diffractograms of the $\mathrm{Fe}_{3} \mathrm{O}_{4}, \mathrm{MNP}-\mathrm{Au}$ seeds and MNP-AuNS samples. The diffraction features that appear at $30^{\circ}, 35.5^{\circ}, 43^{\circ}, 54^{\circ}, 57.5^{\circ}$ and $47.5^{\circ}$ correspond to the (220), (311), (400), (422), (511), and (440) planes, respectively, of the inverse spinel structure of magnetite (JCPDS file no. 19-0629) (International Centre for Diffraction Data-Powder Diffraction File (ICDDPDF) No. 00-005-0566). The difractograms (a) and (b), corresponding to MNP-AuNS and MNP-Au seeds particles show four additional peaks assigned to the (111), (200), (220) and (311) planes of Au NPs with the face-centered cubic (fcc) structure (indicated with grey bars in Figure 3) (JCPDS Card No. 04-0784). The XRD patterns for MNP-AuNS particles present an additional peak at $34^{\circ}$, which matches with the (104) plane of hematite (JCPDS Card 33-0664). This small amount of hematite $\left(\alpha-\mathrm{Fe}_{2} \mathrm{O}_{3}\right)$ can be attributed to oxidation of surface iron sites due to reduction of $\mathrm{Ag}^{+}$adsorbate ions during AuNS growth. 


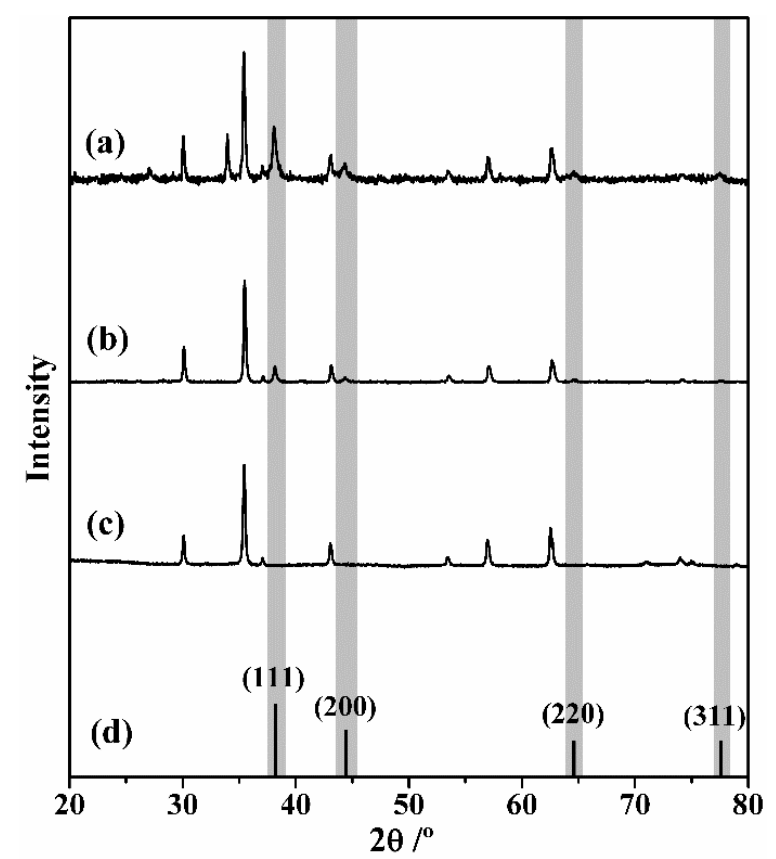

Figure 3. Powder XRD diffraction patterns of (a) MNP-AuNS NPs; (b) MNP-Au seeds; (c); $\mathrm{Fe}_{3} \mathrm{O}_{4} \mathrm{NPs}$; and (d) reported reflexions for crystalline gold with fcc structure (JCPDS Card No. 04-0784).

\subsection{Uptake of TC from Aqueous Solutions Using MNP-AuNS Nanosorbents}

The molecular structure of TC comprises a four-fused-ring structure (Figure 4a), whereas ring D is aromatic but rings $A, B$, and $C$ include saturated carbon centres. This three-dimensional architecture is almost planar (rings B, C and D are planar) including a kink between rings $A$ and B (Figure $4 b$ ) [55]. Figure $4 \mathrm{c}$ shows the UV-Vis spectrum of TC aqueous solutions $(10 \mu \mathrm{M})$, which presents a multiplet of bands with maximum absorption wavelengths peaked at $250 \mathrm{~nm}, 278 \mathrm{~nm}$ and $358 \mathrm{~nm}$ corresponding mainly to $\pi \rightarrow \pi^{*}$ transitions.

The performance of the hybrid nanomaterials in the uptake of TC from aqueous solutions was assessed at variable $\mathrm{pH}$ values and for different contact times. First, the effect of the contact time on the adsorption capacity of MNP-AuNS, for the initial antibiotic concentration of $10 \mu \mathrm{M}$ at $\mathrm{pH} 5-6$, is shown in Figure 5. Pure $\mathrm{Fe}_{3} \mathrm{O}_{4}$ particles and the MNP-AuNS composite were dispersed in aqueous solutions of TC $(10 \mu \mathrm{M})$ for $20 \mathrm{~min}$ and $24 \mathrm{~h}$, respectively, and then the materials were recovered by magnetic separation from the solution. The amount of adsorbed TC was indirectly evaluated by UV-Vis measurements performed on the supernatants. 
(a)<smiles>CN(C)[C@H]1C(O)=C(C(N)=O)C(O)[C@]2(O)C(O)=C3C(=O)c4c(O)cccc4[C@@](C)(O)[C@@]3(C)C[C@@H]12</smiles>

(b)

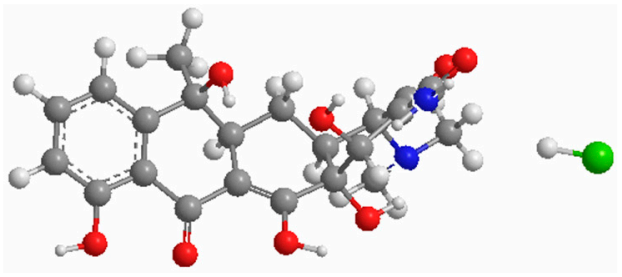

(c)

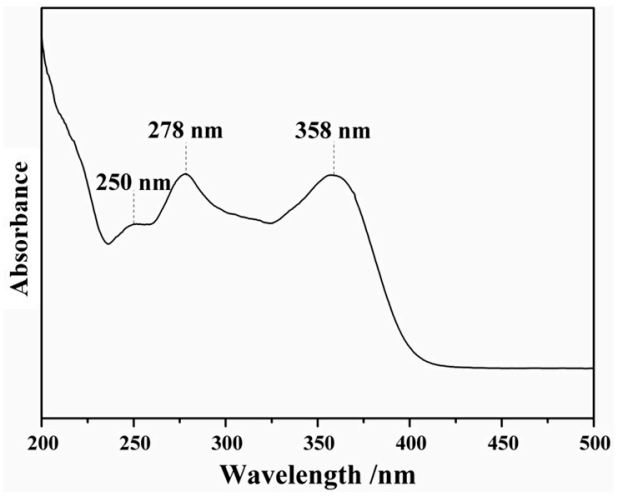

Figure 4. (a) Structural formula and (b) ball-and-stick representation of a TC molecule; and (c) visible spectrum of an aqueous solution of TC.

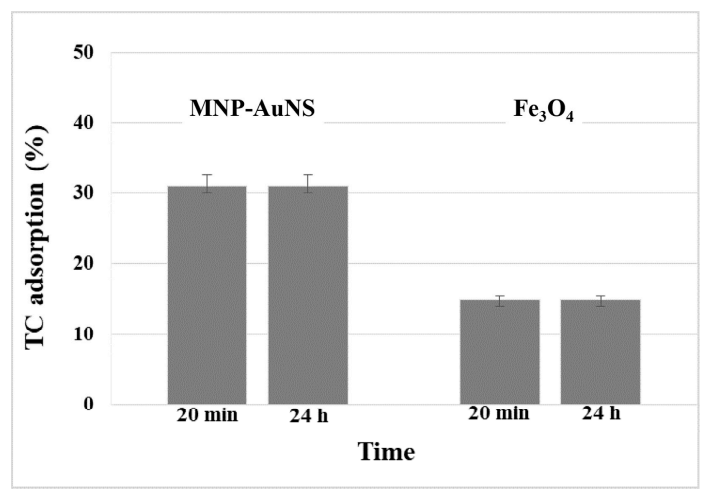

Figure 5. Amount of TC adsorbed on $\mathrm{Fe}_{3} \mathrm{O}_{4} \mathrm{NPs}$ and MNP-AuNS, for an initial concentration of 10 $\mu \mathrm{M}$ in the antibiotic.

The adsorption of TC using $\mathrm{Fe}_{3} \mathrm{O}_{4}$ NPs reached around 15\%, either after 20 min or $24 \mathrm{~h}$. On the other hand, the MNP-AuNS particles adsorbed 31\% of TC dissolved in the original solution, after $20 \mathrm{~min}$ and $24 \mathrm{~h}$ contact times. Control experiments carried out in parallel in the absence of sorbent particles under the same conditions of $\mathrm{pH}$ and contact time have demonstrated no losses of TC. Hence, the decrease of TC concentration in solution when contacted with sorbent particles was ascribed to adsorption phenomena. These results also suggest that the adsorption of TC had increased due to the presence of the Au nanostars at the surface of the magnetic particles. 
TC is an amphoteric molecule with three functional groups that confer a marked pH-dependent behaviour on solubility [56]. Figure S3 shows the molecular structure and pKa values for tetracycline (see Supplementary Materials). TC presents an amphoteric behaviour due to the presence of ionisable functional groups and possesses three acidity constants. The first deprotonation involves the C1-C3 tricarbonyl methane ( $\mathrm{pKa}=3.3$ ), leading to the zwitterionic form of the neutral compound. The second $\mathrm{pKa}(\mathrm{pKa}=7.7)$ is due to the deprotonation of the ketophenolic hydroxyl groups in C10 and C12. Above $\mathrm{pH}$ 9.6, TC exists in the aqueous solution as a divalent anion due to the neutralization of the C4-protonated dimethylamino group. This knowledge on the pKa constants gives an indication about the chemical species of TC in the solutions under analysis and is also relevant to inquire about the molecular forms that might interact with the colloidal particulates. In these regards, the surface charge of the $\mathrm{Fe}_{3} \mathrm{O}_{4}$ and MNP-AuNS is also important and the isoelectric points were found to be 5 and 4 , respectively.

The influence of $\mathrm{pH}$ on the performance of the MNP-AuNS as sorbents for TC was studied in the $\mathrm{pH}$ range 2-10 for a contact time of $20 \mathrm{~min}$ (Figure 6). Control experiments were performed in the same conditions using neat $\mathrm{Fe}_{3} \mathrm{O}_{4}$ particles. The adsorption of TC onto MNP-AuNS increased at $\mathrm{pH}$ values between 4 and 6, above which the trend was reversed. As expected, in a strong acidic solution ( $\mathrm{pH}$ <3.3), the electrostatic repulsion between the cationic moieties of TC and positive surfaces of $\mathrm{Fe}_{3} \mathrm{O}_{4}$ and of MNP-AuNS led to low TC adsorption. When the $\mathrm{pH}$ of the suspension was higher than the isoelectric point of the sorbents $\left(\mathrm{Fe}_{3} \mathrm{O}_{4}\right.$ : $\mathrm{pH}$ 5; MNP-AuNS: $\left.\mathrm{pH} 4\right)$, the negative charges on the surfaces of $\mathrm{Fe}_{3} \mathrm{O}_{4}$ and MNP-AuNS interact with cationic TC. Thus, the adsorption increased with increasing $\mathrm{pH}$ and reached a maximum at approximately $\mathrm{pH} 5$ and $\mathrm{pH}$ 6, using $\mathrm{Fe}_{3} \mathrm{O}_{4}$ and $\mathrm{MNP}-\mathrm{AuNS}$, respectively, and then decreased with the further increase of $\mathrm{pH}$. Indeed, under alkaline conditions, there was a reduction of adsorbed TC due to electrostatic repulsions between negatively charged TC and the adsorbents. Thus, the most favourable $\mathrm{pH}$ range for $\mathrm{TC}$ adsorption onto the MNP-AuNS sorbents was observed at $\mathrm{pH} 5-6$. Although the adsorption of TC at such a $\mathrm{pH}$ window is the most favourable, it still occurs at other $\mathrm{pH}$ values due to the presence of other type of interactions between the TC adsorbates and the particles' surfaces. In fact, the observed sorption behaviour can be explained by taking into account a combination of electrostatic interactions and covalent type/inner sphere-type interactions [57-62]. The latter explaining the adsorption of TC at low pH values, where both NPs and TC are positively charged, and also at $\mathrm{pH}>7$, where both the particles' surface charge and TC species are negative.

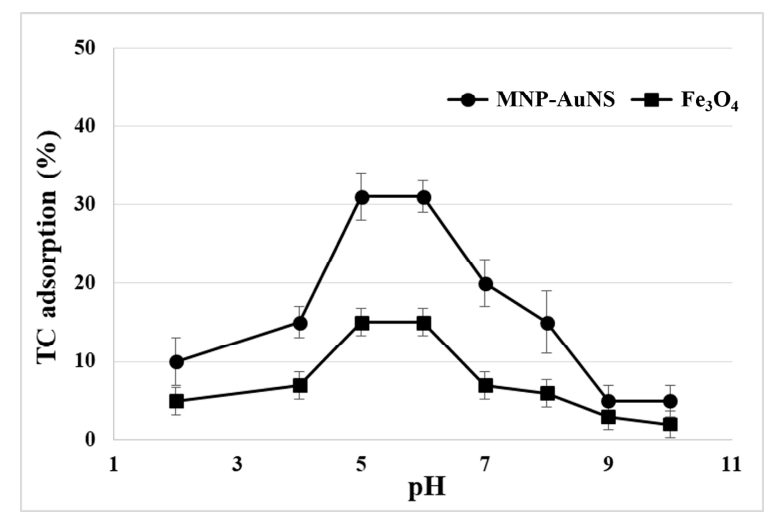

Figure 6. Effect of $\mathrm{pH}$ of the medium on the TC uptake, for an initial TC concentration of $10 \mu \mathrm{M}$ and a contact time of $20 \mathrm{~min}$.

\subsection{SERS Detection of Tetracycline Using MNP-AuNS Substrates}

Figure 7 shows the SERS spectrum of TC on MNP-AuNS substrates and the Raman spectrum of TC powder is also shown for the sake of comparison. Figure S4 (Supplementary Materials) shows the Raman spectra of TC aqueous solutions $(0.1 \mathrm{M}$ and $10 \mu \mathrm{M})$ and MNP-AuNS powder. Note that 
MNP-AuNS originates low-background signal in the Raman spectrum and does not interfere with TC detection (Figure S4c, Supplementary Materials). The Raman spectrum of a TC aqueous solution $(0.1 \mathrm{M})$ shows pronounced bands at 1619, 1447, 1315 and $1172 \mathrm{~cm}^{-1}$ (Figure S4b, Supplementary Materials), but these bands are not observed in more diluted conditions $(10 \mu \mathrm{M})$ used in the SERS experiments. Additionally, no Raman bands were observed for TC of which aqueous solution $(10 \mu \mathrm{M})$ was contacted with $\mathrm{Fe}_{3} \mathrm{O}_{4}$ NPs for 20 min (Figure S4d, Supplementary Materials). Similar experiments using colloid of Au nanostars (i.e., without magnetite) as SERS substrate did not provide any Raman signal for TC, which highlights the advantage in using a combination of the AuNS with the magnetite particles in the hybrid nanostructures.

The SERS enhancement depends on several factors such as the morphology (size and shape) of the nanostructures, the excitation wavelength and the aggregation state of the nanoparticles as a mean for the formation of hotspots [21]. Some authors have also described off-resonant effects to explain the SERS effect for conditions, in which the laser wavelength is red-shifted in relation the LSPR band $[63,64]$.

In our case, it is not obvious to consider an off-resonant effect due to the closeness energies of the excitation line to the LSPR band. In addition, the use of MNP-Au seeds as platforms did not show any Raman signal from adsorbed TC (Figure S4e, Supplementary Materials), which is consistent with a less favourable particle shape for hotspot formation (when compared to the stars). It has been reported that AuNSs have higher local electromagnetic fields on the tips due to the presence of hotspots at sharp edges of the NPs, thus producing strong Raman enhancement [65]. These observations are in line with our results.

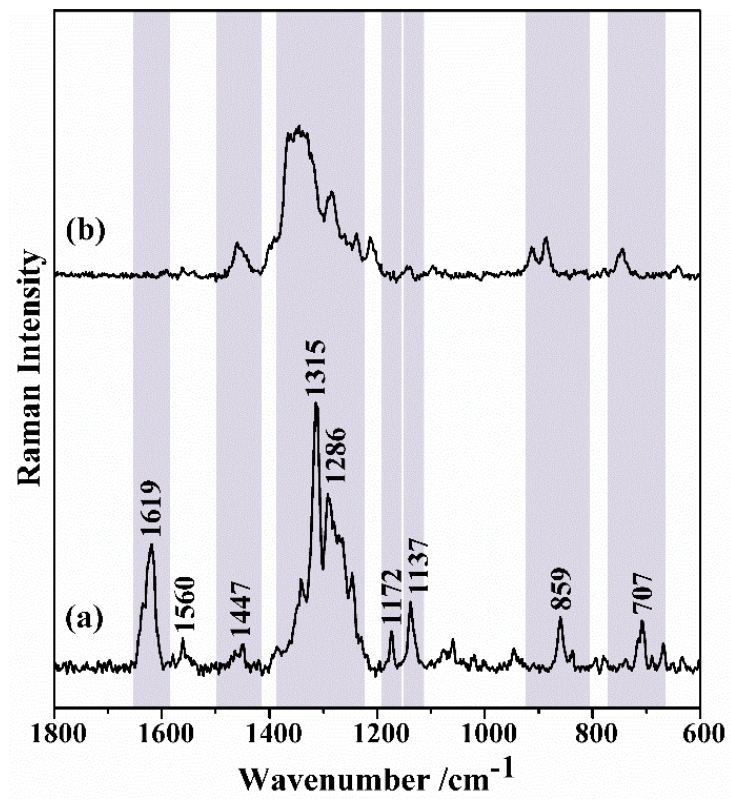

Figure 7. (a) Raman spectrum of tetracycline powder; (b) SERS spectrum of TC onto MNP-AuNS after contacting this sorbent with a solution of TC $(10 \mu \mathrm{M})$. Grey bars highlight Raman bands observed for both the TC powder and TC adsorbed onto MNP-AuNS.

The SERS spectrum of TC onto MNP-AuNS substrates shows most of the bands in accordance with the conventional Raman spectrum of TC powder but pronounced band broadening is also observed (Figure 7). In particular, the bands at 747, 888, 1347 and $1459 \mathrm{~cm}^{-1}$, which correspond to normal modes that involve the CO stretching from rings B, C and D, are clearly observed (Table 1). In addition, most of the bands in the SERS spectrum are shifted in comparison to those observed in the Raman spectra of TC in powder and TC in the aqueous solution (0.1 M). In SERS, charge transfer is a short-range mechanism that occurs when the molecular analyte is chemisorbed at the surface of a metal $[67,68]$. Although in this case the TC molecules are retained onto the metal surface, 
charge transfer also results in the weakening or deformation of molecular bonds. The dissociation of the $\mathrm{O}-\mathrm{H}$ bond and formation of the $\mathrm{O}-\mathrm{Au}$ bond result in a more pronounced Raman shift for the deformation-coupled $\mathrm{C}-\mathrm{O}$ stretching modes of rings $\mathrm{B}, \mathrm{C}$ and $\mathrm{D}$. The absence of the Raman band at $1619 \mathrm{~cm}^{-1}$ assigned to vibrational modes that involve both the amide- $\mathrm{NH}_{2}$ moiety and the secondary amine of the dimethylamino group suggests that these groups of TC are not directly interacting with the AuNS surfaces. In fact, as discussed above, this is in accordance with the assumption that the protonated dimethylamino groups $(\mathrm{pH} 5)$ interact preferentially with negative surface moieties of the iron oxide via electrostatic interactions, as schematically illustrated in Figure 8. However, the sorption attachment of TC onto MNPs' surface, involving $\pi$-cation bonding between Fe (II and III) ions and aromatic $\pi$-electrons of TC, cannot be discarded [69].

Table 1. Raman bands and respective assignments for the TC powder and TC adsorbed onto MNP-AuNS used as SERS substrates [24,25,27-29,55,66].

Raman $\left(\mathrm{cm}^{-\mathbf{1}}\right)$

Figure 8. Schematic illustration showing TC molecules interacting with the hybrid nanostructures composed of AuNS and $\mathrm{Fe}_{3} \mathrm{O}_{4}$ particles.

Figure 8 relates to the TC molecules directly attached to the particles' surfaces (first layer). Additionally, the formation of overstacked TC assemblies, due to $\pi-\pi$ stacking interactions between neutral $\mathrm{H}_{3} \mathrm{TC}$ molecules, can also explain the higher adsorption of TC at this $\mathrm{pH}$ window. This is consistent with the observation of strong SERS signals of the aromatic $\mathrm{C}=\mathrm{C}$ backbone [70]. 
Raman spectroscopy coupled with imaging methods combines both spectral and spatial information and thus allows for the localized identification of TC species in the substrate. In order to explore the spatial distribution and spectral information of the TC molecules onto MNP-AuNS material, 2D surface Raman imaging was acquired for the best SERS operational conditions (Figure 9). High-resolution Raman imaging was performed by raster-scanning the laser beam over a surface area of $400 \mu^{2}$ and accumulating a full Raman spectrum at each pixel (in total 22500 spectra), with a spatial resolution of approximately $0.13 \mu \mathrm{m}$. The integration of the absolute area underneath the TC characteristic band at $1347 \mathrm{~cm}^{-1}$ was used to establish the colour intensity scale in the Raman map. Thus, the brighter colours correspond to a higher Raman band intensity of TC and consequently its location in the MNP-AuNS surface.

As compared to metal colloidal nanostructures used in SERS studies, such as Ag NPs or Au NPs, the use of solids poses issues concerning the homogeneity of the substrates. In order to make sure that the observed Raman signals are ascribed to an SERS effect due to the presence of the AuNS, all the measurements were performed by using $\mathrm{Fe}_{3} \mathrm{O}_{4}$ particles as the substrate in control experiments (spectrum presented in Figure S4d (Supplementary Materials)). Moreover, the spectra were considered as representative after analysing several areas of the substrate using Raman mapping and also by randomly selecting points on the substrate and recording the corresponding SERS spectra (Figure 9b). Although these results show slight changes in the Raman intensities, it is clear that at this scale the SERS signals are always observed, regardless of the region analysed.

(a)

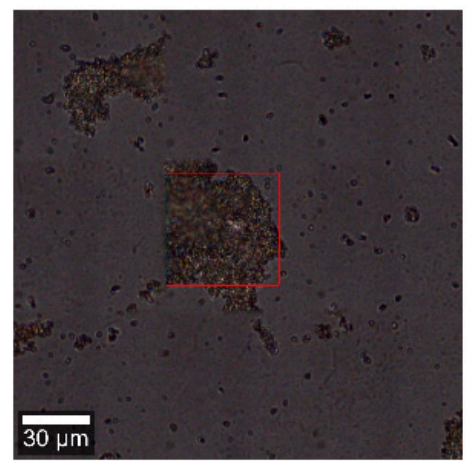

(b)

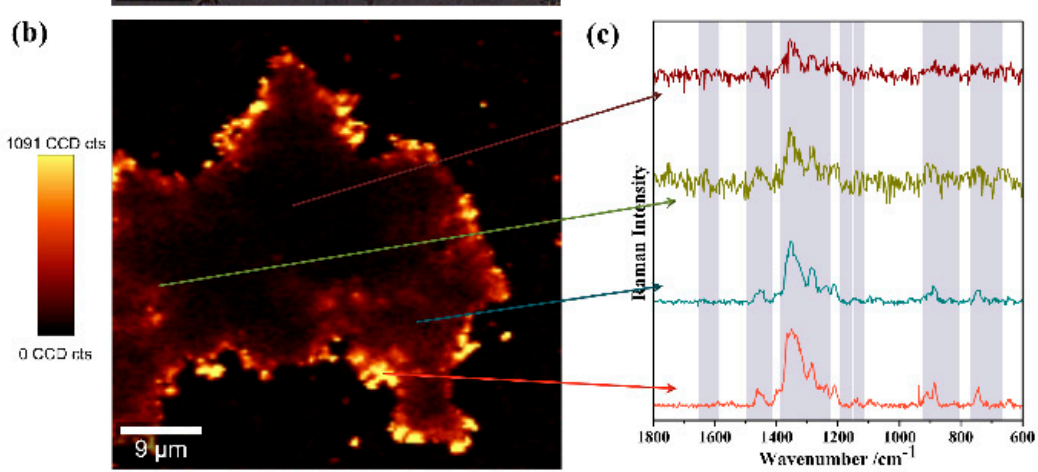

(c)

Figure 9. (a) Optical image of the MNP-AuNS hybrid substrates after contact with TC, with the Raman scanned area marked in red; (b) Raman image obtained using the integrated intensity of the Raman band at $1347 \mathrm{~cm}^{-1}$ in the SERS spectrum of TC $(10 \mu \mathrm{M})$ using the MNP-AuNS as substrates; and (c) selected SERS spectra of TC collected at different points as shown by the arrows. The vertical bar shows the colour profile with the relative intensity scale.

Note that the tips of the AuNS provide strong localized electromagnetic field (hotspots) in the hybrid substrates. Thus, it is possible that the application of the magnetic gradient on the substrates could provide an arrangement of the MNP-AuNS particles that also originates regions of strong Raman signal enhancement. This point was investigated in more detail by comparing the SERS sensitivity of adsorbed TC on MNP-AuNS before and after the magnetic gradient. In more detail, the 
sample was deposited on a glass slide (Figure S5a, Supplementary Materials) and the Raman spectrum acquired, then a NdFeB laboratorial magnet was placed below the glass side to induce an external magnetic gradient (Figure S5b, Supplementary Materials) and the Raman spectrum acquired. In this case, no significant changes were observed in the Raman bands of TC presented on the collected SERS spectra but a better signal-to-noise ratio was obtained for the sample submitted to magnetic gradient (Figure S5b, Supplementary Materials). This result might indicate creation of hotspots induced by aggregation due to the external magnetic gradient.

In order to assess the SERS sensitivity of the MNP-AuNS for TC, samples of aqueous solutions with variable concentrations of antibiotic have been analysed (10 $\mu \mathrm{M}$ to $10 \mathrm{nM}, \mathrm{pH}$ ). Figure 10 shows the Raman spectra of TC obtained by the variation of the concentration, using MNP-AuNS as substrate and the correspondent Raman map by monitoring the band intensity at $1347 \mathrm{~cm}^{-1}$. The TC seems localized in preferential regions of the scanned area, which is more clearly observed for samples of lower TC concentration. As the concentration of TC increased, the antibiotic content became more homogenously distributed on the surface of the substrate with increasing brighter areas in the scanned area. Figure $10 \mathrm{~d}$ shows that in these conditions the SERS intensity of the TC bands tended to decrease as the TC concentration decreased from $10 \mu \mathrm{M}$ to $10 \mathrm{nM}$. It is noteworthy that the SERS signal for TC was observed for a concentration as low as $10 \mathrm{nM}$. This result demonstrates that Raman mapping combined with SERS analysis offers a powerful technique to detect vestigial TC in spiked water by using the hybrid nanomaterials described here.

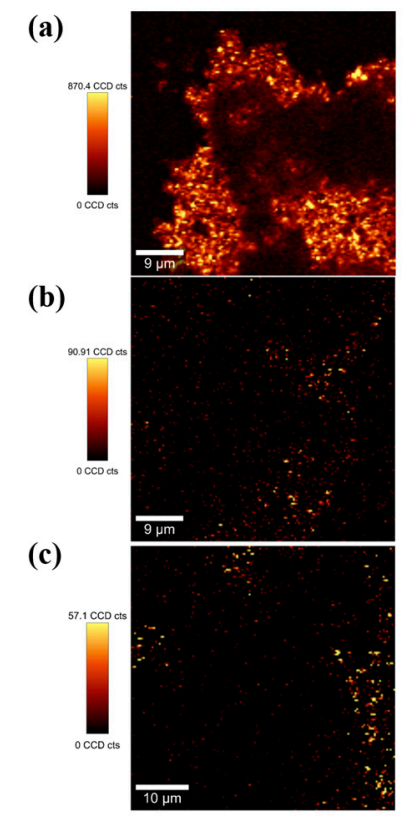

(d)

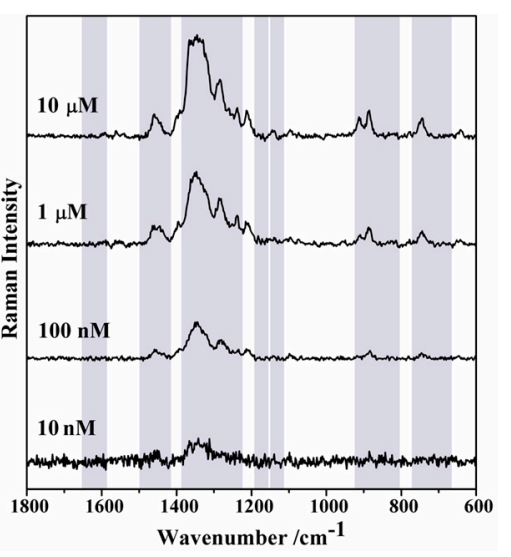

Figure 10. Raman images obtained with the integrated intensity of the band at $1347 \mathrm{~cm}^{-1}$ of TC recorded using MNP-AuNS as SERS substrate using different TC concentrations: (a) $1 \mu \mathrm{M}$; (b) $100 \mathrm{nM}$; and (c) $10 \mathrm{nM}$. The vertical bar shows the colour profile in each image, with the relative intensity scale. (d) Single SERS spectra of TC taken from the Raman images using different TC concentrations.

\subsection{SERS Detection of Tetracycline in More Complex Spiked Aqueous Matrices}

The vast majority of the studies reporting the SERS detection of antibiotics in water were carried out using ultrapure water. However, salted waters are the last receptors of such pollutants and the source of water used in many aquacultures. In order to investigate the reliability of these SERS substrates using natural waters, the SERS detection of TC was performed using more complex spiked aqueous samples using estuarine water from the Aveiro lagoon (A) and mineral water from Serra do Buçaco (B). Thus, a series of spiked waters with different TC concentrations have been contacted with MNP-AuNS, using experimental conditions similar to those described above. Figure 11 presents 
Raman images corresponding to the SERS spectra of TC adsorbed on MNP-AuNS particles that have contacted with natural waters A and B. The SERS images show the spatial distribution of TC molecules on the MNP-AuNS substrate, in which the brighter areas correspond to an increase of the Raman signal of the TC molecules due to the presence of active Raman scattering sites. The SERS spectra in Figure 11c are single Raman spectra taken from the bright spots observed in the respective Raman images of Figure 11a,b (1 acquisition, $0.1 \mathrm{~s}$ ). The Raman spectra of the MNP-AuNS substrate with (A) estuarine water from Aveiro lagoon (salty water) and (B) mineral water are presented in the Figure S6 for comparative purposes.
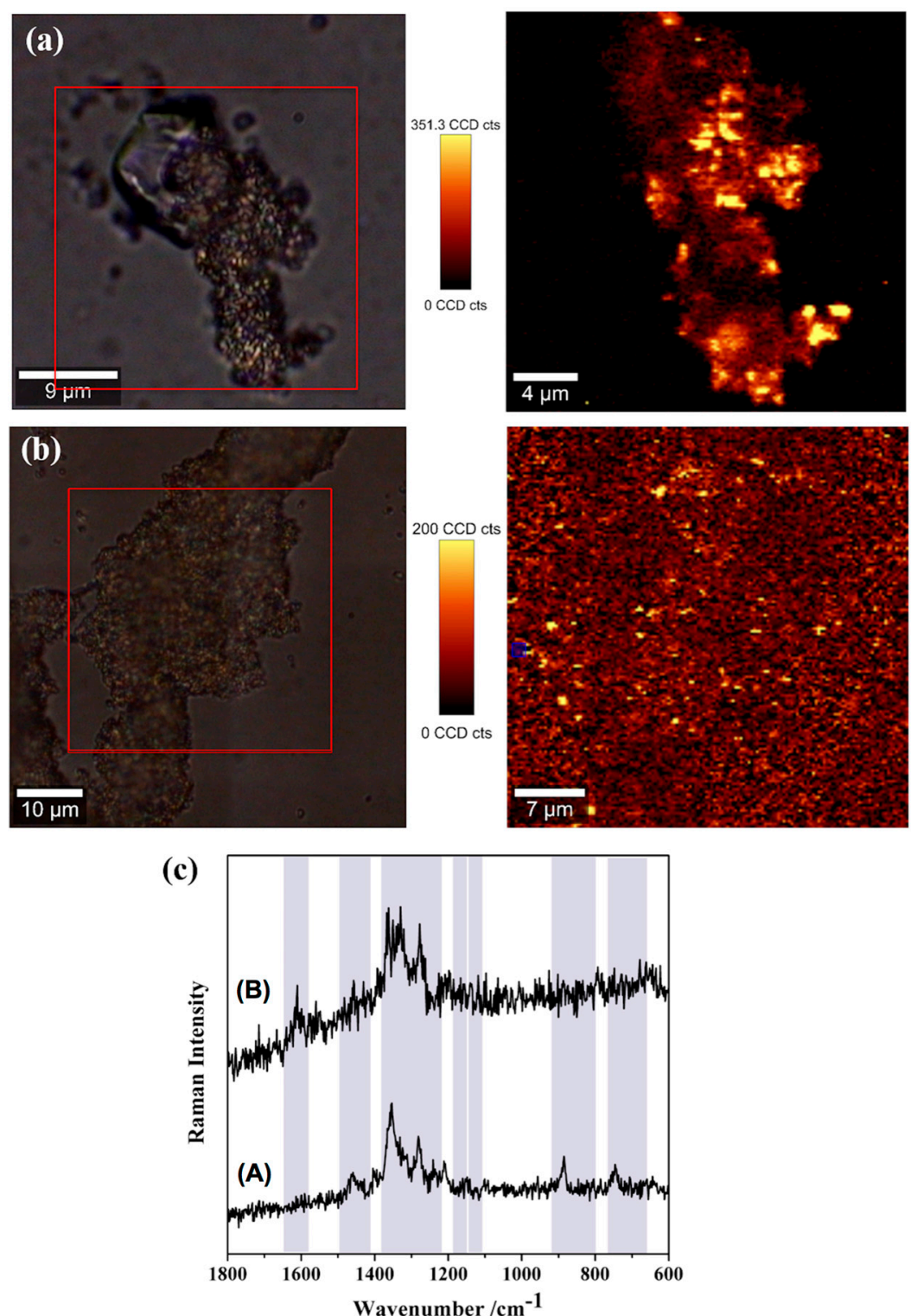

Figure 11. Raman images obtained using the integrated intensity of the band at $1347 \mathrm{~cm}^{-1}$ in the SERS spectra of TC $(10 \mu \mathrm{M})$ recorded using the MNP-AuNS as substrates (excitation at $633 \mathrm{~nm}, 0.2 \mathrm{~mW}$ laser power) for the TC spiked samples: (a) estuarine water from Aveiro lagoon and (b) mineral water. The respective optical images of the samples are on the left side, with the scanned area marked in red. The vertical bar shows the colour profile in each image, with the relative intensity scale; and (c) single SERS spectrum for TC $(10 \mu \mathrm{M})$ using MNP-AuNS obtained from the Raman images above for (A) estuarine water from Aveiro lagoon and (B) mineral water. 
This result demonstrates that the MNP-AuNS nanosorbents reported here are effective for the uptake and subsequently SERS detection of TC dissolved in more complex matrices, such as salted waters. In fact, the Raman spectra acquired from the collected maps using both water samples (A and B) are similar to the Raman spectrum of TC shown in Figure 7b. It should be noticed that for the experiment with mineral water sample, an additional Raman band is observed at $1619 \mathrm{~cm}^{-1}$ in the SERS spectrum of TC (Figure 11c, spectrum B), which is assigned to the amide stretching and bending modes in ring A. A possible explanation for this observation is related to the presence of competing cations not only for surface sites of magnetite but also for TC complexation [71], limiting the interaction of TC molecules with the iron oxide and thus leaving amide groups free to interact with the SERS-active Au surfaces. The detection limit of TC in both salted water samples was $1 \mu \mathrm{M}$ (Figure S7, Supplementary Materials), thus being inferior to the value obtained for the laboratorial samples but demonstrating that the MNP-AuNS nanomaterials are effective for SERS detection of TC detection in more complex aqueous matrices.

\section{Materials and Methods}

\subsection{Materials}

The following chemicals were used as purchased: ferrous sulfate heptahydrate $\left(\mathrm{FeSO}_{4} \cdot 7 \mathrm{H}_{2} \mathrm{O}\right.$, $>99 \%$, Panreac, Barcelona, Spain), potassium nitrate $\left(\mathrm{KNO}_{3},>99 \%\right.$, Sigma-Aldrich, St. Louis, $\mathrm{MO}, \mathrm{USA})$, sodium citrate tribasic dihydrate $\left(\mathrm{Na}_{3} \mathrm{C}_{6} \mathrm{H}_{5} \mathrm{O}_{7} \cdot 2 \mathrm{H}_{2} \mathrm{O}, 99 \%\right.$, Sigma-Aldrich), chloroauric acid trihydrate $\left(\mathrm{HAuCl}_{4} \cdot 3 \mathrm{H}_{2} \mathrm{O}, \geq 99.9 \%\right.$, Sigma-Aldrich) and potassium hydroxide $(\mathrm{KOH},>86 \%$, Sigma-Aldrich), ascorbic acid $\left(\mathrm{C}_{6} \mathrm{H}_{8} \mathrm{O}_{6}, \mathrm{~J}\right.$. M. Vaz Pereira, Lisboa, Portugal), silver nitrate $\left(\mathrm{AgNO}_{3}\right.$, 99.9\%, Sigma-Aldrich), acid chloride ( $\mathrm{HCl}, 37 \%$, AnaloR Normapur, VWR International, Radnor, PA, USA), and tetracycline hydrocloride (TC, $\mathrm{C}_{22} \mathrm{H}_{24} \mathrm{~N}_{2} \mathrm{O}_{8}$, Sigma-Aldrich). All the solutions were freshly prepared using ultrapure water $(18.2 \mathrm{~m} \Omega \cdot \mathrm{cm})$.

\subsection{Synthesis of $\mathrm{Fe}_{3} \mathrm{O}_{4}$ Nanoparticles}

Magnetite particles were synthesized by the hydrolysis of $\mathrm{FeSO}_{4} \cdot 7 \mathrm{H}_{2} \mathrm{O}$, as described elsewhere [49]. Briefly, a solution containing $20 \mathrm{~g}$ of $\mathrm{FeSO}_{4} \cdot 7 \mathrm{H}_{2} \mathrm{O}$ in $140 \mathrm{~mL}$ of deionized water previously flushed with $\mathrm{N}_{2}$, was boiled at $90^{\circ} \mathrm{C}$. Then, a solution of $1.62 \mathrm{~g} \mathrm{KNO}_{3}$ and $11.23 \mathrm{~g} \mathrm{KOH}$ in $60 \mathrm{~mL} \mathrm{H}_{2} \mathrm{O}$ was added dropwise for $5 \mathrm{~min}$ to the $\mathrm{Fe}$ (II) solution, under nitrogen bubbling. The black powder obtained was stirred over $1 \mathrm{~h}$ at $90{ }^{\circ} \mathrm{C}$, left overnight and then washed with water and separated magnetically.

\subsection{Synthesis of MNP-Au Seeds}

The MNP-Au seeds were synthesized by a modified method described elsewhere [50]. Briefly, cubic magnetite nanoparticles $(60 \mathrm{mg})$ were dispersed in ultrapure water $(50 \mathrm{~mL})$ and then the solution was sonicated in the ultra-sound bath for 10 minutes, and then left immersed in an ice bath, over $15 \mathrm{~min}$ under sonication (horn Sonics, Vibracell, Newtown, CT, USA). A HAuCl ${ }_{4}$ solution $(80 \mu \mathrm{L}, 158.3 \mathrm{mM})$ was added and the mixture was mechanically stirred for $30 \mathrm{~min}$ at $500 \mathrm{rpm}$. Then, the solution was heated to $90{ }^{\circ} \mathrm{C}$, and $500 \mu \mathrm{L}$ of sodium citrate $(1.0 \mathrm{M})$ was added dropwise. The above boiling mixture was stirred for 1 hour, forming MNP-Au colloidal seed particles.

\subsection{Synthesis of MNP-AuNS Nanocomposite}

The MNP-AuNS nanocomposites were synthesized by a seed growth method [50]. Briefly, $200 \mu \mathrm{L}$ of the as-prepared MNP-Au seeds colloid was added to $10 \mathrm{~mL}$ of a $0.25 \mathrm{mM} \mathrm{HAuCl}_{4}$ solution, followed by $5 \mu \mathrm{L}$ of $1 \mathrm{M} \mathrm{HCl}$ at room temperature and mixed by gentle inversion for 5 seconds. Then, $100 \mu \mathrm{L}$ of silver nitrate $(8 \mathrm{mM})$ and $50 \mu \mathrm{L}$ of ascorbic acid $(100 \mathrm{mM})$ were simultaneously added. The solution was mixed by gentle inversion for 20 seconds as its colour rapidly turned from light yellow to blue. 
The MNP-AuNS nanocomposites particles were magnetically separated from the colloidal solution and dispersed in ultrapure water.

\subsection{Adsorption Experiments of TC onto MNP-AuNS}

The amount of adsorbed TC at the MNP-AuNS particles was determined by the interpolation of $\mathrm{UV}$ absorption of the supernatant at $358 \mathrm{~nm}$. The performance of the hybrid particles was investigated for the same antibiotic concentration $(10 \mu \mathrm{M})$ at $\mathrm{pH} 5-6$, with $20 \mathrm{~min}$ and $24 \mathrm{~h}$ contact times. Hence, $10 \mathrm{~mL}$ of TC solution was added to $0.25 \mathrm{mg}$ of MNP-AuNS. These mixtures were then incubated using a mini-rotor at room temperature. The influence of the $\mathrm{pH}$ solution on TC adsorption was evaluated at variable $\mathrm{pH}$ values, from 2 to 11 . Generally, the $\mathrm{pH}$ of a TC solution $(10 \mathrm{~mL}, 10 \mu \mathrm{M})$ was adjusted to the required value by adding $\mathrm{HCl}$ or $\mathrm{NaOH}$. Then, $0.25 \mathrm{mg}$ of MNP-AuNS were added and dispersed, and the batch experiment was run in the conditions described above, for a period of $20 \mathrm{~min}$. The final concentration of TC was determined by UV-Vis spectroscopy. The $\mathrm{pH}$ of the solution was also measured at the end of the adsorption experiment to confirm that no $\mathrm{pH}$ significant variations arise from the addition of the MNPs.

\subsection{SERS Measurements}

The SERS study was performed by adding the as-synthesized particles $(0.25 \mathrm{mg})$ to aqueous solutions of TC $(10 \mathrm{~mL})$ with different concentrations $(10 \mu \mathrm{M}-10 \mathrm{nM})$. The mixtures were incubated for 20 minutes, using a mini-rotor, at room temperature to allow for the adsorption of TC to the surfaces of AuNS. The samples were then magnetically separated from the solution using a magnet and the MNP-AuNS particles were washed twice with ultrapure water. Particles were transferred to glass sides for SERS analysis and characterization and dried at room temperature. For all the SERS measurements, the pure magnetite particles were also used as the control sample. SERS measurements have been performed in different areas of the nanocomposites in order to check the reproducibility of the measurements. In order to assess the performance of the MNP-AuNS under ionic competition conditions, a more complex aqueous samples spiked with TC was also analysed: estuarine water from Aveiro lagoon (seawater) and mineral water from Serra do Buçaco. We have analysed five different samples (MNP-AuNS), in which we have used different MNP-Au seeds and different MNP-AuNS batch for the detection of TC in ultrapure water, three samples for estuarine water from Aveiro lagoon and two samples for mineral water from Serra do Buçaco.

Raman images obtained using the WITec Alpha $300 \mathrm{RA}+$ were produced by raster-scanning the laser beam over a surface area of $20 \times 20 \mu \mathrm{m}^{2}$ and accumulating a full Raman spectrum at each pixel (in total 22500 spectra), with a spatial resolution of approximately $0.13 \mu \mathrm{m}$. The integration of the absolute area underneath the TC characteristic band at $1347 \mathrm{~cm}^{-1}$ was used to establish the colour intensity scale in the Raman map. A laser wavelength of $633 \mathrm{~nm}$ with a laser power of $0.2 \mathrm{~mW}$ was used. A $100 \times$ objective was used to view samples, and the integration time for each spectrum was $0.1 \mathrm{~s}$. The time required to create Raman images using each integration time was $44 \mathrm{~min}$. All the Raman spectra were data treated with background subtraction using the Project 5 programme that are available with the confocal Raman microscope (WITec, Ulm, Germany).

\subsection{Instrumentation}

The TC concentration in the supernatant was determined spectrophotometrically by monitoring the absorbance at $358 \mathrm{~nm}$ spectrophotometrically using a Jasco U-560 UV-Vis spectrophotometer (Jasco Inc., Easton, MD, USA). Linear calibration was used for quantification based on the curves between the concentration and peak intensity of a known standard of TC. TEM was carried out on a Hitachi H-9000 TEM microscope (Hitachi, Tokyo, Japan) operating at $300 \mathrm{kV}$. The TEM samples were prepared by placing a drop of the diluted colloid on a carbon-coated copper grid and the solvent was left to evaporate in air. The XRD data were collected using a PAN analytical Empyrean X-ray diffractometer (PANanalytical, Almelo, The Netherlands) equipped with $\mathrm{Cu} \mathrm{K \alpha}$. The XRD data were collected using 
a PAN analytical Empyrean Xan aliquot of the aqueous suspension of the hybrid nanostructure on a silicon holder. Raman spectral imaging was performed in a combined Raman-AFM-SNOM confocal microscope WITec alpha300 RAS+ at CICECO (WITec, Ulm, Germany), in the Chemistry Department of the University of Aveiro. A Nd:YAG laser operated at $633 \mathrm{~nm}$.

\section{Conclusions}

In conclusion, we have developed new hybrid nanomaterials comprising plasmonic nanoparticles (Au nanostars) supported on magnetic solid ( $\mathrm{Fe}_{3} \mathrm{O}_{4}$ particles). These hybrid nanostructures were investigated as colloidal nanosorbents for subsequent SERS analysis of tetracycline in water samples. This research has demonstrated that this type of composite nanostructures shows great potential for water monitoring and purification, including the application to more complex aqueous matrices, containing a number of organic and inorganic interfering species such as salted waters. We anticipate that this type of hybrid nanomaterials can be applied to the analysis of TC in other types of fluids, provided the adequate sample preparation is performed. Overall, the MNP-AuNS particles can be regarded as multifunctional platforms for vestigial analysis, biological detection and environmental monitoring, due to their ability for pollutant uptake using magnetic separation and subsequent detection using Raman methods.

Supplementary Materials: The following are available online at http:/ www.mdpi.com/2079-4991/9/1/31/s1, Figure S1: Zeta potential measurements of cubic-shaped magnetite particles in function of pH; Figure S2: Optical spectra of MNP-Au seeds, Au seeds, MNP, MNP-AuNSs and AuNSs (supernatant); Figure S3: Structures and pKa values of tetracyclines; Figure S4: Raman spectra of (a) TC aqueous solution $(0.1 \mathrm{M})$; (b) tetracycline aqueous solution $(10 \mu \mathrm{M})$; (c) Mag-AuNS solid substrate; (d) $\mathrm{Fe}_{3} \mathrm{O}_{4}$ nanoparticles after contact with TC for 20 min at an initial concentration of $10 \mu \mathrm{M}$; (e) Mag-Au seeds nanoparticles after contact with TC for 20 min at an initial concentration of $10 \mathrm{Mm}$; Figure S5: SERS spectra for TC $(10 \mu \mathrm{M})$ using Mag-AuNS (a) before and (b) after the magnetic concentration (excitation at $633 \mathrm{~nm}, 0.2 \mathrm{~mW}$ laser power). Grey shadow: characteristic Raman bands for TC powder; Figure S6: Average Raman spectra of Mag-AuNS substrate with (a) estuarine water from Aveiro lagoon (salty water) and (b) mineral water (excitation at $633 \mathrm{~nm}, 0.2 \mathrm{~mW}$ laser power, $22500 \mathrm{spectra}, 0.1 \mathrm{~s}, 1$ acquisition); Figure S7: SERS spectra of TC at several concentrations using MNP-AuNS as the SERS substrate in (a) estuarine water from Aveiro lagoon and (b) mineral water.

Author Contributions: P.C.P. performed the laboratory work, including the synthesis, tetracycline adsorption experiments, Raman spectroscopy studies and general characterization of all the materials. S.F. designed the experiments and performed the Raman confocal microscopy experiments. T.T. and H.I.S.N. supervised the research. All the authors have analysed the data and made contributions to the writing of the paper.

Funding: This work was developed within the scope of the project CICECO-Aveiro Institute of Materials, POCI-01-0145-FEDER-007679 (FCT Ref. UID/CTM/50011/2013), and when appropriate co-financed by European Regional Development Fund (FEDER) under the PT2020 Partnership Agreement. P. C. Pinheiro thanks the Fundação para a Ciência e Tecnologia (FCT) for the PhD grant SFRH/BD/96731/2013. S. Fateixa thanks FCT for the grant SFRH/BPD/93547/2013.

Conflicts of Interest: The authors declare no conflict of interest.

\section{References}

1. Boxall, A.B.A.; Kolpin, D.W.; Halling-Sørensen, B.; Tolls, J. Are veterinary medicines causing environmental risks? Environ. Sci. Technol. 2003, 37, 286A-294A. [CrossRef] [PubMed]

2. Granados-Chinchilla, F.; Rodríguez, C. Tetracyclines in food and feedingstuffs: From regulation to analytical methods, bacterial resistance, and environmental and health implications. J. Anal. Methods Chem. 2017, 2017, 1-24. [CrossRef] [PubMed]

3. Carvalho, I.T.; Santos, L. Antibiotics in the aquatic environments: A review of the European scenario. Environ. Int. 2016, 94, 736-757. [CrossRef] [PubMed]

4. Lei, M.; Zhang, L.; Lei, J.; Zong, L.; Li, J.; Wu, Z.; Wang, Z. Overview of emerging contaminants and associated human health effects. BioMed Res. Int. 2015, 2015, 1-12. [CrossRef] [PubMed]

5. Nelson, M.L.; Levy, S.B. The history of the tetracyclines. Ann. N. Y. Acad. Sci. 2011, 1241, 17-32. [CrossRef] [PubMed]

6. Duggar, B.M. Aureomycin: A product of the continuing search for new antibiotics. Ann. N. Y. Acad. Sci. 1948, 51, 177-181. [CrossRef] [PubMed] 
7. European Medicines Agency (EMA). Sales of Veterinary Antimicrobial Agents in 30 European Countries in 2015. Available online: https:/ / www.ema.europa.eu/documents/report/seventh-esvac-report-salesveterinary-antimicrobial-agents-30-european-countries-2015_en.pdf (accessed on 14 November 2018).

8. Daghrir, R.; Drogui, P. Tetracycline antibiotics in the environment: A review. Environ. Chem. Lett. 2013, 11, 209-227. [CrossRef]

9. Bottoni, P.; Caroli, S. Presence of residues and metabolites of pharmaceuticals in environmental compartments, food commodities and workplaces: A review spanning the three-year period 2014-2016. Microchem. J. 2018, 136, 2-24. [CrossRef]

10. Commission, E. No 37/2010 of 22 December 2009 on pharmacologically active substances and their classification regarding maximum residue limits in foodstuffs of animal origin. Off. J. Eur. Union 2010, L15, 1-72.

11. Kowalski, P. Capillary electrophoretic method for the simultaneous determination of tetracycline residues in fish samples. J. Pharm. Biomed. Anal. 2008, 47, 487-493. [CrossRef] [PubMed]

12. Croubels, S.; Van Peteghem, C.; Baeyens, W. Sensitive spectrofluorimetric determination of tetracycline residues in bovine milk. Analyst 1994, 119, 2713-2716. [CrossRef] [PubMed]

13. Fritz, J.W.; Zuo, Y. Simultaneous determination of tetracycline, oxytetracycline, and 4-epitetracycline in milk by high-performance liquid chromatography. Food Chem. 2007, 105, 1297-1301. [CrossRef]

14. Zhang, Y.; Lu, S.; Liu, W.; Zhao, C.; Xi, R. Preparation of anti-tetracycline antibodies and development of an indirect heterologous competitive enzyme-linked immunosorbent assay to detect residues of tetracycline in milk. J. Agric. Food Chem. 2007, 55, 211-218. [CrossRef] [PubMed]

15. Song, E.; Yu, M.; Wang, Y.; Hu, W.; Cheng, D.; Swihart, M.T.; Song, Y. Multi-color quantum dot-based fluorescence immunoassay array for simultaneous visual detection of multiple antibiotic residues in milk. Biosens. Bioelectron. 2015, 72, 320-325. [CrossRef]

16. Conzuelo, F.; Campuzano, S.; Gamella, M.; Pinacho, D.G.; Reviejo, A.J.; Marco, M.P.; Pingarrón, J.M. Integrated disposable electrochemical immunosensors for the simultaneous determination of sulfonamide and tetracycline antibiotics residues in milk. Biosens. Bioelectron. 2013, 50, 100-105. [CrossRef]

17. Dang, P.K.; Degand, G.; Danyi, S.; Pierret, G.; Delahaut, P.; Ton, V.D.; Maghuin-Rogister, G.; Scippo, M.-L. Validation of a two-plate microbiological method for screening antibiotic residues in shrimp tissue. Anal. Chim. Acta 2010, 672, 30-39. [CrossRef]

18. Moskovits, M. Surface-enhanced Raman spectroscopy: A brief retrospective. J. Raman Spectrosc. 2005, 36, 485-496. [CrossRef]

19. Kneipp, H.; Kneipp, K. Surface-enhanced hyper Raman scattering in silver colloidal solutions. J. Raman Spectrosc. 2005, 36, 551-554. [CrossRef]

20. Kneipp, K. Surface-enhanced raman scattering. Phys. Today 2007, 60, 40-46. [CrossRef]

21. Fateixa, S.; Nogueira, H.I.S.; Trindade, T. Hybrid nanostructures for SERS: Materials development and chemical detection. Phys. Chem. Chem. Phys. 2015, 17, 21046-21071. [CrossRef]

22. Schlücker, S. Surface-enhanced raman spectroscopy: Concepts and chemical applications. Angew. Chem. 2014, 53, 4756-4795. [CrossRef] [PubMed]

23. Li, H.; Chen, Q.; Hassan, M.M.; Chen, X.; Ouyang, Q.; Guo, Z.; Zhao, J. A magnetite/PMAA nanospheres-targeting SERS aptasensor for tetracycline sensing using mercapto molecules embedded core/shell nanoparticles for signal amplification. Biosens. Bioelectron. 2017, 92, 192-199. [CrossRef] [PubMed]

24. Zhao, J.; Liu, P.; Yuan, H.; Peng, Y.; Hong, Q.; Liu, M. Rapid detection of tetracycline residues in duck meat using surface enhanced raman spectroscopy. J. Spectrosc. 2016, 2016, 1-6. [CrossRef]

25. Qu, L.-L.; Liu, Y.-Y.; Liu, M.; Yang, G.-H.; Li, D.-W.; Li, H. Highly reproducible Ag NPs/CNT-intercalated GO membranes for enrichment and SERS detection of antibiotics. ACS Appl. Mater. Interfaces 2016, 8, 28180-28186. [CrossRef] [PubMed]

26. Meng, F.; Ma, X.; Duan, N.; Wu, S.; Xia, Y.; Wang, Z.; Xu, B. Ultrasensitive SERS aptasensor for the detection of oxytetracycline based on a gold-enhanced nano-assembly. Talanta 2017, 165, 412-418. [CrossRef] [PubMed]

27. Dhakal, S.; Chao, K.; Huang, Q.; Kim, M.; Schmidt, W.; Qin, J.; Broadhurst, C.L. A simple surface-enhanced Raman spectroscopic method for on-site screening of tetracycline residue in whole milk. Sensors 2018, 18, 424. [CrossRef] 
28. Filgueiras, A.L.; Paschoal, D.; Dos Santos, H.F.; Sant'Ana, A.C. Adsorption study of antibiotics on silver nanoparticle surfaces by surface-enhanced Raman scattering spectroscopy. Spectrochim. Acta Part A Mol. Biomol. Spectrosc. 2015, 136, 979-985. [CrossRef] [PubMed]

29. Jin, D.; Bai, Y.; Chen, H.; Liu, S.; Chen, N.; Huang, J.; Huang, S.; Chen, Z. SERS detection of expired tetracycline hydrochloride with an optical fiber nano-probe. Anal. Methods 2015, 7, 1307-1312. [CrossRef]

30. Lee, S.; Kumar, P.; Hu, Y.; Cheng, G.J.; Irudayaraj, J. Graphene laminated gold bipyramids as sensitive detection platforms for antibiotic molecules. Chem. Commun. 2015, 51, 15494-15497. [CrossRef]

31. Li, R.; Zhang, H.; Chen, Q.-W.; Yan, N.; Wang, H. Improved surface-enhanced Raman scattering on micro-scale Au hollow spheres: Synthesis and application in detecting tetracycline. Analyst 2011, 136, 2527-2532. [CrossRef]

32. Pinheiro, P.C.; Daniel-da-Silva, A.L.; Nogueira, H.I.S.; Trindade, T. Functionalized inorganic nanoparticles for magnetic separation and SERS detection of water pollutants. Eur. J. Inorg. Chem. 2018, 2018, 3443-3461. [CrossRef]

33. Pinheiro, P.C.; Fateixa, S.; Trindade, T. SERS detection of penicillin G using magnetite decorated with gold nanoparticles. Magnetochemistry 2017, 3, 32. [CrossRef]

34. Reguera, J.; Aberasturi, D.J.; Winckelmans, N.; Langer, J.; Bals, S.; Liz-Marzán, L.M. Synthesis of Janus plasmonic-magnetic, star-sphere nanoparticles, and their application in SERS detection. Faraday Discuss. 2016, 191, 47-59. [CrossRef] [PubMed]

35. Neng, J.; Tan, J.; Jia, K.; Sun, P. A fast and cost-effective detection of melamine by surface enhanced Raman spectroscopy using a novel hydrogen bonding-assisted supramolecular matrix and gold-coated magnetic nanoparticles. Appl. Sci. 2017, 7, 475. [CrossRef]

36. Zhang, L.; Xu, J.; Mi, L.; Gong, H.; Jiang, S.; Yu, Q. Multifunctional magnetic-plasmonic nanoparticles for fast concentration and sensitive detection of bacteria using SERS. Biosens. Bioelectron. Bioelectron. 2012, 31, 130-136. [CrossRef]

37. Fan, Z.; Senapati, D.; Khan, A.S.; Singh, A.K.; Hamme, A.; Yust, B.; Sardar, D.; Ray, P.C. Popcorn-shaped magnetic core-plasmonic shell multifunctional nanoparticles for the targeted magnetic separation and enrichment, label-free SERS imaging, and photothermal destruction of multidrug-resistant bacteria. Chem. Eur. J. 2013, 19, 2839-2847. [CrossRef] [PubMed]

38. He, Q.; Zhao, A.; Li, L.; Sun, H.; Wang, D.; Guo, H.; Sun, M.; Chen, P. Fabrication of $\mathrm{Fe}_{3} \mathrm{O}_{4} @ \mathrm{SiO}_{2} @ \mathrm{Ag}$ magnetic-Plasmonic nanospindles as highly efficient SERS active substrates for label-free detection of pesticides. New J. Chem. 2017, 41, 1582-1590. [CrossRef]

39. Wang, J.; Wu, X.; Wang, C.; Rong, Z.; Ding, H.; Li, H.; Li, S.; Shao, N.; Dong, P.; Xiao, R.; et al. Facile synthesis of Au-coated magnetic nanoparticles and their application in bacteria detection via a SERS method. ACS Appl. Mater. Interfaces 2016, 8, 19958-19967. [CrossRef]

40. Wang, C.; Xu, J.; Wang, J.; Rong, Z.; Li, P.; Xiao, R.; Wang, S. Polyethylenimine-interlayered silver-shell magnetic-core microspheres as multifunctional SERS substrates. J. Mater. Chem. C 2015, 3, 8684-8693. [CrossRef]

41. Yu, W.; Huang, Y.; Pei, L.; Fan, Y.; Wang, X.; Lai, K. Magnetic $\mathrm{Fe}_{3} \mathrm{O}_{4} / \mathrm{Ag}$ hybrid nanoparticles as surface-enhanced raman scattering substrate for trace analysis of furazolidone in fish feeds. J. Nanomater. 2014, 2014, 1-8. [CrossRef]

42. Li, H.; Li, C.; Martin, F.L.; Zhang, D. Diagnose pathogens in drinking water via magnetic surface-enhanced Raman scattering (SERS) assay. Mater. Today Proc. 2017, 4, 25-31. [CrossRef]

43. Du, J.; Jing, C. Preparation of thiol modified $\mathrm{Fe}_{3} \mathrm{O}_{4} @ \mathrm{Ag}$ magnetic SERS probe for PAHs detection and identification. J. Phys. Chem. C 2011, 115, 17829-17835. [CrossRef]

44. Kibar, G.; Topal, A.E.; Dana, A.; Tuncel, A. Newly designed silver coated-magnetic, monodisperse polymeric microbeads as SERS substrate for low-level detection of amoxicillin. J. Mol. Struct. 2016, 1119, 133-138. [CrossRef]

45. Tang, S.; Li, Y.; Huang, H.; Li, P.; Guo, Z.; Luo, Q.; Wang, Z.; Chu, P.K.; Li, J.; Yu, X.-F. Efficient enrichment and self-assembly of hybrid nanoparticles into removable and magnetic SERS substrates for sensitive detection of environmental pollutants. ACS Appl. Mater. Interfaces 2017, 9, 7472-7480. [CrossRef]

46. Hou, T.; Liu, Y.; Xu, L.; Wu, Y.; Ying, Y.; Wen, Y.; Guo, X.; Yang, H. Au dotted magnetic graphene sheets for sensitive detection of thiocyanate. Sens. Actuators B Chem. 2017, 241, 376-382. [CrossRef] 
47. Sun, Y.; Xu, L.; Zhang, F.; Song, Z.; Hu, Y.; Ji, Y.; Shen, J.; Li, B.; Lu, H.; Yang, H. A promising magnetic SERS immunosensor for sensitive detection of avian influenza virus. Biosens. Bioelectron. 2017, 89, 906-912. [CrossRef]

48. Tavares, D.S.; Daniel-da-Silva, A.L.; Lopes, C.B.; Silva, N.J.O.; Amaral, V.S.; Rocha, J.; Pereira, E.; Trindade, T. Efficient sorbents based on magnetite coated with siliceous hybrid shells for removal of mercury ions. J. Mater. Chem. A 2013, 1, 8134-8143. [CrossRef]

49. Girginova, P.I.; Daniel-da-Silva, A.L.; Lopes, C.B.; Figueira, P.; Otero, M.; Amaral, V.S.; Pereira, E.; Trindade, T. Silica coated magnetite particles for magnetic removal of $\mathrm{Hg}(2+)$ from water. J. Colloid Interface Sci. 2010, 345, 234-240. [CrossRef]

50. Wang, Y.; Polavarapu, L.; Liz-Marzán, L.M. Reduced graphene oxide-supported gold nanostars for improved SERS sensing and drug delivery. ACS Appl. Mater. Interfaces 2014, 6, 21798-21805. [CrossRef]

51. Sau, T.K.; Rogach, A.L.; Döblinger, M.; Feldmann, J. One-step high-yield aqueous synthesis of size-tunable multispiked gold nanoparticles. Small 2011, 7, 2188-2194. [CrossRef]

52. Liu, M.; Guyot-Sionnest, P. Mechanism of silver(I)-assisted growth of gold nanorods and bipyramids. J. Phys. Chem. B 2005, 109, 22192-22200. [CrossRef] [PubMed]

53. Orendorff, C.J.; Murphy, C.J. Quantitation of metal content in the silver-assisted growth of gold nanorods. J. Phys. Chem. B 2006, 110, 3990-3994. [CrossRef] [PubMed]

54. Quaresma, P.; Osório, I.; Dória, G.; Carvalho, P.A.; Pereira, A.; Langer, J.; Araújo, J.P.; Pastoriza-Santos, I.; Liz-Marzán, L.M.; Franco, R.; et al. Star-shaped magnetite@gold nanoparticles for protein magnetic separation and SERS detection. RSC Adv. 2014, 4, 3659-3667. [CrossRef]

55. Leypold, C.F.; Reiher, M.; Brehm, G.; Schmitt, M.O.; Schneider, S.; Matousek, P.; Towrie, M. Tetracycline and derivatives-assignment of IR and Raman spectra via DFT calculations. Phys. Chem. Chem. Phys. 2003, 5, 1149-1157. [CrossRef]

56. Sarmah, A.K.; Meyer, M.T.; Boxall, A.B.A. A global perspective on the use, sales, exposure pathways, occurrence, fate and effects of veterinary antibiotics (VAs) in the environment. Chemosphere 2006, 65, 725-759. [CrossRef] [PubMed]

57. Gu, C.; Karthikeyan, K.G. Interaction of tetracycline with aluminum and iron hydrous oxides. Environ. Sci. Technol. 2005, 39, 2660-2667. [CrossRef] [PubMed]

58. Figueroa, R.A.; Mackay, A.A. Sorption of oxytetracycline to iron oxides and iron oxide-rich soils. Environ. Sci. Technol. 2005, 39, 6664-6671. [CrossRef]

59. Zhang, D.; Niu, H.; Zhang, X.; Meng, Z.; Cai, Y. Strong adsorption of chlorotetracycline on magnetite nanoparticles. J. Hazard. Mater. 2011, 192, 1088-1093. [CrossRef]

60. Zhao, Y.; Geng, J.; Wang, X.; Gu, X.; Gao, S. Adsorption of tetracycline onto goethite in the presence of metal cations and humic substances. J. Colloid Interface Sci. 2011, 361, 247-251. [CrossRef]

61. Rakshit, S.; Sarkar, D.; Elzinga, E.J.; Punamiya, P.; Datta, R. Surface complexation of oxytetracycline by magnetite: Effect of solution properties. Vadose Zone J. 2014, 13, 1-10. [CrossRef]

62. Rakshit, S.; Sarkar, D.; Punamiya, P.; Datta, R. Kinetics of oxytetracycline sorption on magnetite nanoparticles. Int. J. Environ. Sci. Technol. 2014, 11, 1207-1214. [CrossRef]

63. Kuttner, C. Plasmonics in Sensing: From Colorimetry to SERS Analytics. In Plasmonics; Gric, T., Ed.; IntechOpen: London, UK, 2018. [CrossRef]

64. Sivapalan, S.T.; DeVetter, B.M.; Yang, T.K.; van Dijk, T.; Schulmerich, M.V.; Carney, P.S.; Rohit Bhargava, R.; Murphy, C.J. Off-resonance surface-enhanced Raman spectroscopy from gold nanorod suspensions as a function of aspect ratio: Not what we thought. ACS Nano 2013, 7, 2099-2105. [CrossRef] [PubMed]

65. Rodríguez-Lorenzo, L.; Álvarez-Puebla, R.N.A.; Pastoriza-Santos, I.; Mazzucco, S.; Stéphan, O.; Kociak, M.; Liz-Marzán, L.M.; García de Abajo, F.J. Zeptomol Detection Through Controlled Ultrasensitive Surface-Enhanced Raman Scattering. J. Am. Chem. Soc. 2009, 131, 4616-4618. [CrossRef]

66. Chen, X.; Liang, W.; Yang, C.; Lin, W.; Bi, M. Simultaneous quantitative detection of tetracyclines derivatives by Raman spectroscopy. In Proceedings of the 2012 IEEE International Conference on Virtual Environments Human-Computer Interfaces and Measurement Systems (VECIMS) Proceedings, Tianjin, China, 2-4 July 2012; pp. 111-114. [CrossRef]

67. Osawa, M.; Matsuda, N.; Yoshii, K.; Uchida, I. Charge transfer resonance Raman process in surface-enhanced Raman-scattering from p-aminothiophenol adsorbed on silver-Herzberg-Teller contribution. J. Phys. Chem. 1994, 98, 12702-12707. [CrossRef] 
68. Suzuki, S.; Kaneko, S.; Fujii, S.; Marqués-González, S.; Nishino, T.; Kiguchi, M. Effect of the molecule-metal interface on the surface-enhanced Raman scattering of 1,4-benzenedithiol. J. Phys. Chem. C 2016, 120, 1038-1042. [CrossRef]

69. Okoli, C.P.; Naidoo, E.B.; Ofomaja, A.E. Role of synthesis process variables on magnetic functionality, thermal stability, and tetracycline adsorption by magnetic starch nanocomposite. Environ. Nanotechnol. Monit. Manag. 2018, 9, 141-153. [CrossRef]

70. Mecheri, B.; Gambinossi, F.; Nocentini, M.; Puggelli, M.; Caminati, G. Modulation of tetracycline-phospholipid interactions by tuning of $\mathrm{pH}$ at the water-air interface. Biophys. Chem. 2004, 111, 15-26. [CrossRef]

71. Morandi, S.; Focardi, C.; Nocentini, M.; Puggelli, M.; Caminati, G. Development and validation of europium-sensitized luminescence (ESL) method for the determination of tetracycline residues in milk. Food Anal. Methods 2009, 2, 271-281. [CrossRef]

(C) 2018 by the authors. Licensee MDPI, Basel, Switzerland. This article is an open access article distributed under the terms and conditions of the Creative Commons Attribution (CC BY) license (http://creativecommons.org/licenses/by/4.0/). 